Sultan Qaboos University Journal of Arts \& Social Sciences

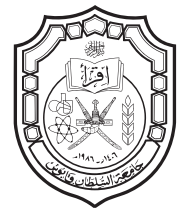

جامعة السلطان قابوس مجلة الآداب والعلوم الاجتماعية

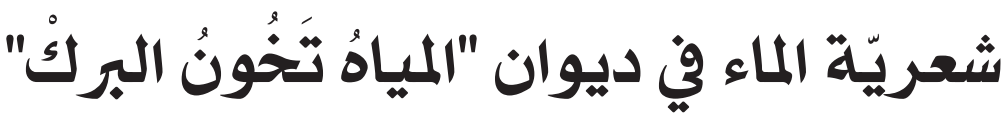 للشاعر الحُماني عوض اللويهي
}

\begin{tabular}{c}
\hline أسماعيل سليمان سالم المزايدة \\
\hline الجامعة الأردنية
\end{tabular}

guefara1981@yahoo.com

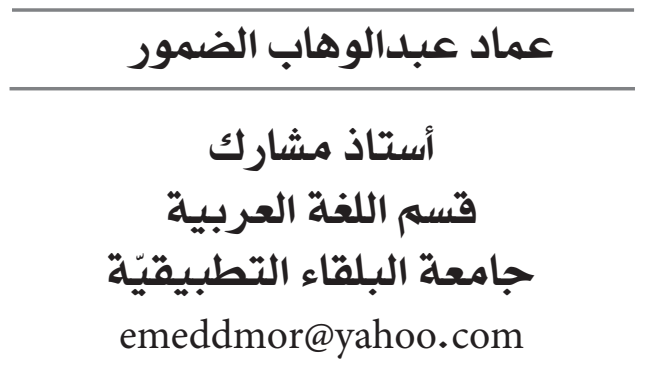

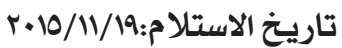

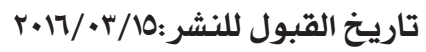




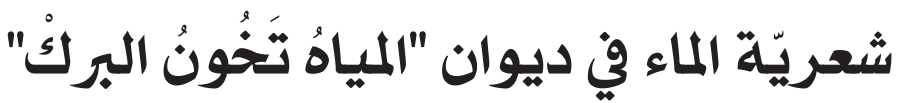 \\ للشاعر العُماني عوض ديوان اللوياهي}

عماد عبدالوهاب الضمور و إسماعيل سليمان سالم المزايدة

الملخص:

ظلهر الماء في القصيدة العربية الحديثة بوصفه مكوّناً بنائيًاً يمتاز بثرائه الدلالي والمعرفي، إذ يتّسع معه المعنى، وتنطلق منه الأفكار، ممّا

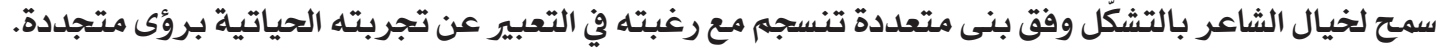

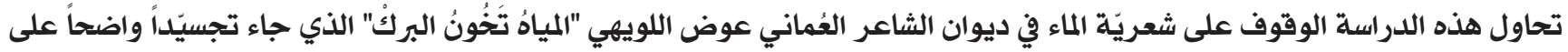
قدرة الشاعر المعاصر على فتح آفاق جلديدة للشعريّة تتوّهج فيها المفردات لإنتاج دلالة جديلدة ذات بعد فكري واضح، وتشكيل فني ناضج تتولّد فيه الصور، وتتعدد معه الدلالة.

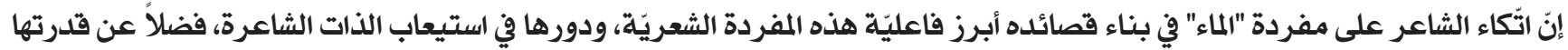
على اختزال مشهد الحياة بكلّ تناقضاته.

الكلمات المفتاحيةة: عوض اللويهي، الماء، الشعرية، قصائد.

\section{The Poetics of Water in the Collection of Poems entitled "Running Water Betrays the Puddles" By the Omani Poet Awadh Al- Luweihi}

Imad Abdel-Wahab Al- Dhmour and Ismail Sulaiman Al-Mozaida

\section{Abstract:}

Water appears in modern Arabic poetry as a semantically distinguished and rich structural component where meanings expand and ideas flow. And this, in turn, enriches the poet's imagination and fulfils his desire to depict his life experience using creative visions.

This study aims to examine the poetics of water in the work of the Omani poet Awadh Al- Luweihi, namely his collection of poems entitled "Running Water Betrays the Puddles" which explicitly embodies the contemporary poet's ability to open new poetic horizons in which rich vocabulary provides texts with new connotations that enjoy an obvious intellectual dimension, and mature artistic craft which creates images and different themes and connotations.

The poet's reliance on the concept of "water" in composing his poetry shows the impact of this poetic theme and its role in the understanding of the poetic self and the ability of portraying life with all its contrasts.

Keywords: Awadh Al- Weihi, water, poetics, poems, Oman. 
فمع ظهور القوة الشعريّة يثقل الماء، ويتعمّق، ويتجسّل، وبالتالي يتطوّر العمل الشعري باتجاه العمق النفسي، باتجاه الجوهر حيث التهاء

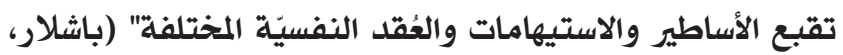

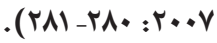
أراد الشاعر لعنوان ديوانه أن يكون ذا مغزى ودلالة مشحونة

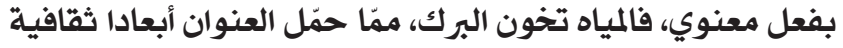
ودينية ونفسية واضحة، يكشف عنها فعل التلقي اللاحق للعنوان. ممّا يعني أن الشاعر "كان محكوماً بقوة العنوان، وبثقله وانها السياقي

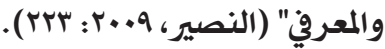
إنّ اشتغال الدلالة في العنوان بفعل الخيانة أحال المياه إلى كينونـة

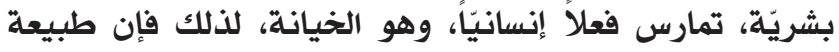
العنوان الاسمية جاءت لتُمارس وظيفة التعيين والتحديل، إذ إذائ ما لبث الفعل المضارع (تخون) أن حطّم هيمنـة الصيغة الاسمية للإفصاح عن فعل الخيانة في الزمن الحاضر، وبشكل يتعاضد

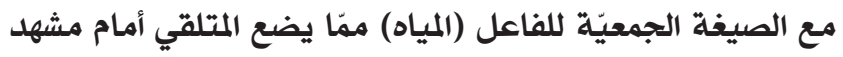
بصري، يبحث عن إجابة لفعل الخيانة الذي تتصف بـه المياه.

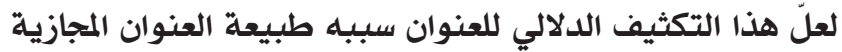

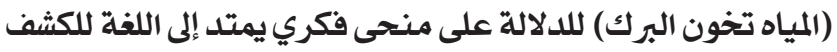
عن رؤى متشظية في النص، فكما يرى (بول ريكور) فإِّ "الاستعارة ليست تزويقاً لفظيًاً للخطاب، بل هي أكثر من قيمة انفي انفعالية، لأنها تعطينا معلومات جليدة، وبوجيز العبارة تخبرنا الاستعارة شيئاً

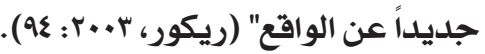

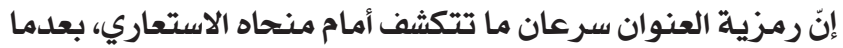

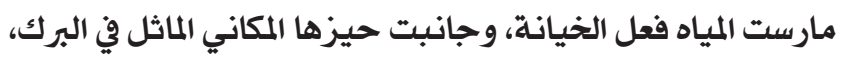
ممّا جعل العنوان يستبدّ بسلطته القائمة على استعارة تصريحية

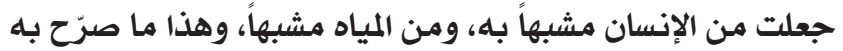

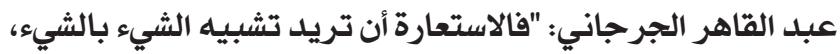

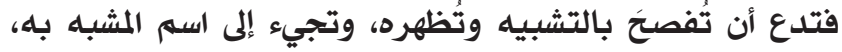

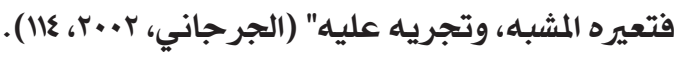

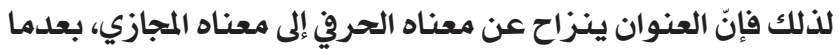
قامت الاستعارة بوظيفتها التعبيريّة القائمة على المباعدة بين ميناه الدال والمدلول"، وكأنّها طعنـة انتقاميّة خاطفة تُسدّد إلى تنافر من

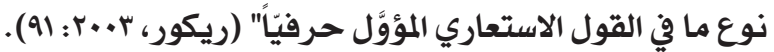

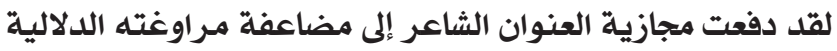
لعنوانات قصائده، لينفلت المعجم اللفظي لسياقات مفردة (المياه)

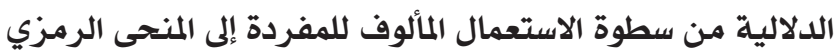
الذي يفك حصار المعنى، ويجعله أكثر إيحاءً.

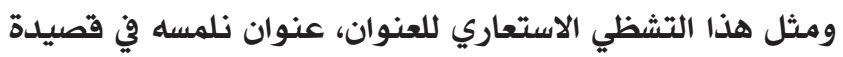
(بلاهة الطيور- حماقة الماء) الذي أسند صفة الحماقة للماء في تصعيد مجازي دال، جعل العنوان حاضراً بوصفه نصاً مستقلاً، ينفتح على المشهد الشعري، ممّا يستدعي تنشيط فاعلية الشئ التلقي لتأويل ما لجأ إليه الشاعر من تعنيف لغوي، جعل الطيور بلهاء،

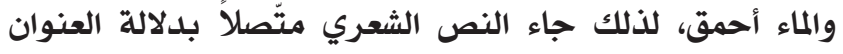
المجازية، كما في قول الشاعر (اللويهي، باء-r : 119): الشجرُ وهو
مقدمة

يعدّ الماء وفق البعد الديني واهب الحياة، وهو في البعد الجغرافي محيط، وبحر، ونهر، ومستنقع، وضمن سياقه الفاعل: فيضان وعاصفة ومطر ... ينبت، ويحيي، ويميت.

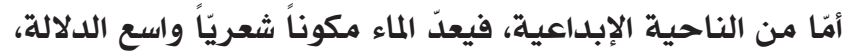

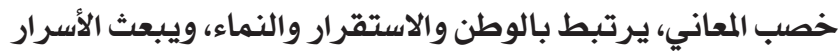
في جسد النص؛ لارتباطه بالثقافات والأديان، وتجسيده لعلاقة الإنسان ببيئته، يزوده بما يحتاجه لحظة لارتباهي بالفقات الفقدان بفاعلية بنائية

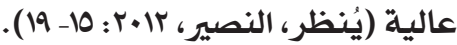
لذلك فإن توظيف الماء في النص الشعري من أهم أشكال التحديث؛

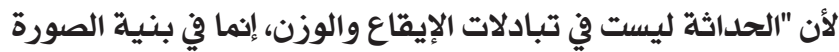

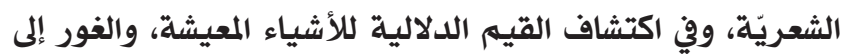

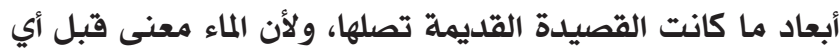

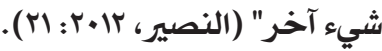

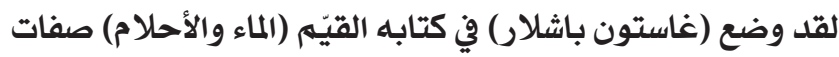
الماء الملهم في النص الشعري، فهو "الماء الذي يتوالد من ذاته، الذهاء الماء الذي

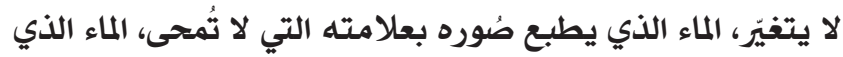

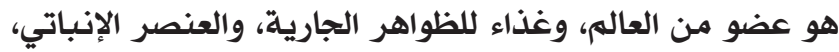

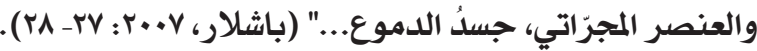
تحاول هذه الدراسة الوقوف على شعريّة الماء في ديوان الشاعر العُماني عوض اللويهي، ممّا يعكس قدرة القصيدة العُمانية على مواكبة حركة الحداثة الشعريّة "والانعتاق من قمهم الاتباع والتقليد، وكان عليها لتحقيق ذلك أن تغيّر جلدها لتحظى بطاقة جديلة تمكنها من ملاحقة سمات القصيدة الحديثة، وهو ما أتاح لها تقنيات فنية أخرجتها من إطارها القديه، ومنحتها إطاراً

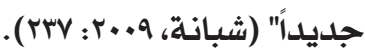
والشاعر عوض اللويهي شاعر عُماني معاصر صلدر ديوانـه الشعري

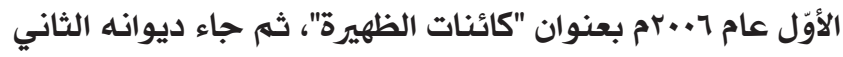
"المياه تخون البرك" الذي يقع في مئتين وعشر صفحات من القطع

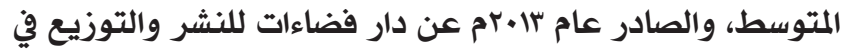

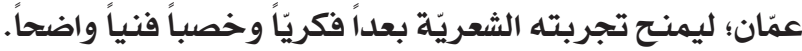
في هذا الديوان ظهر أثر مفردة (الماء) بشكل واضح في البناء الفني للنص الشعري، وقد تجلّى ذلك فيما يلي:

ا- العنوان

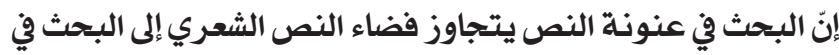
الطبيعة الشعوريّة الحسيّة لإدراك المعطى البصري، والورئي يؤديها العنوان في بنية النص، لما يمتلكه العنوان من قدرة إئية الإدائية، وتأثير بصري في المتلقي، يوجّه فعل القراءة، بوصفه دالاً بصريّاً، يقلّص مساحة البياض فوق النص. يوحي العنوان بعدم خضوع الحياة لمنطق الأشياء، بل هي ذات

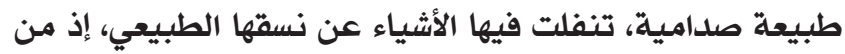

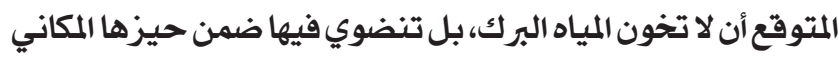
المحدد لها. لكن المياه العميقة العنيفة هي التي تخون؛ لأنّها تولّد

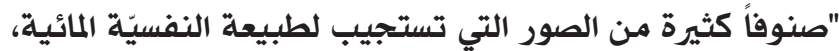


حالة أخرى من التأويل نتيجة لتقاطع الرمز والاستعارة في الرؤيا

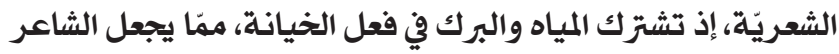

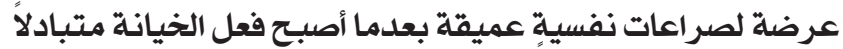
بين الذات والحياة، حيث يقول في قصيدة (خيانة الماء/ خيانة

$$
\begin{aligned}
& \text { البرك) (اللويهي، זا.r٪: 77): } \\
& \text { الضفادعُ تبكي المياه } \\
& \text { وتأمل غيماً يَمُرُ لِّرَ } \\
& \text { ليملأ هذي البركَ } \\
& \text { الضفادعُ } \\
& \text { تتأمل } \\
& \text { ثانيةً } \\
& \text { في المياذ } \\
& \text { وهي تَخَوُنُ البرَكَكْ }
\end{aligned}
$$

إنّ اتخّاذ الشاعر من الماء عالما تحياه الذات الإنسانية سمح بحدوث

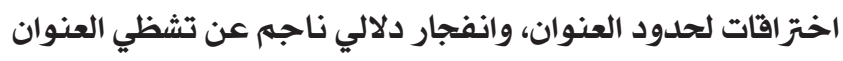
في بنى القصائد، وممارسته ,للعبة إرجاء الدلالات وتأسأجيلها، فهو في كلّ حركة يرتكب دلالة ثم يتنكّر لها في لعبة مثيرة من وناء إخلافه لهوية المعنى، ناسفاً حضوره وتمركزه، وبدلاًا من تأسيسه لدكتاتورية الحضور يسعى العنوان إلى تفتيت هوية المعنى الحنى وتماثلها

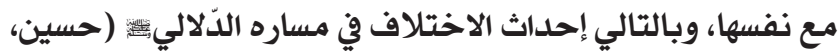
. (rtr:t.. وفي قصيدة (صور مائية للعطش) تنبثق دلالة جديدة للعنوان تلدعم رمزيته، حيث تنبض الصور المائية بتشكلات الحياة،

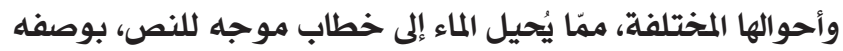

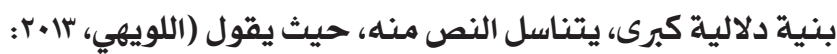
: باني (1ro

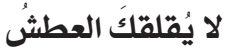

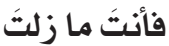

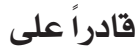
أنْ تردَ النبعَ صافياً بمفردكَ في لحظةِ خاطفة

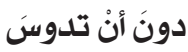
على رقبتك

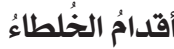
لقد حمل العنوان مفارقة واضحة انعكست في النص الشعري رؤية

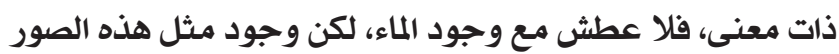

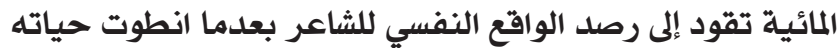
على معاناة، لم تزدها رحلة البحث عن الماء إلا ألماً مضاعفاً.

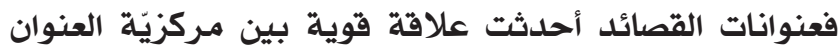

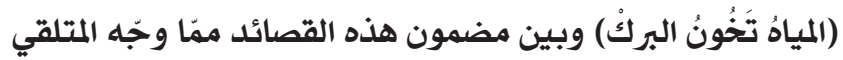
للانتقال من دلالة العنوان المباشرة إلى البحث في أبعاد الماء الدلالية،

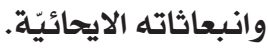

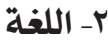
تعذَ الكتابة الإبداعية وسيلة تعبيرية ذات وظيفة نفسيّة واضحة،
وهو يضربُ بعروقِهِ بعيداً

في الصحراء يُدركُ حماقةَ الماءِ لكنَّه يحتاجه

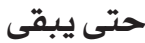
يمتدَ العنوان المركزي للديوان (المياه تخون البرك) إلى باقي عنوانات

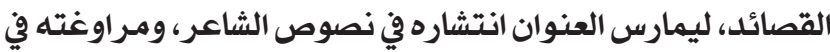

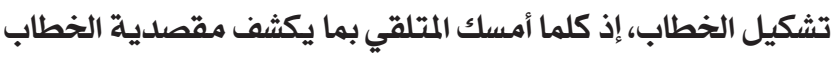

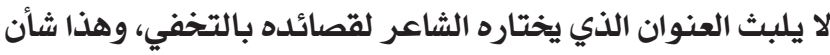

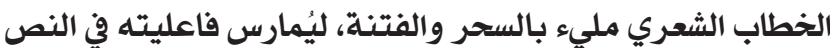

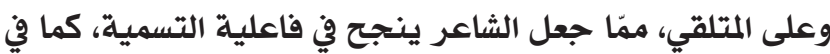

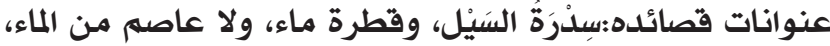

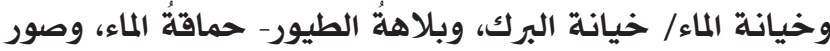

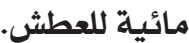
لعلّ انتشار العنوان في النص الشعري أسهـم في تكوين لغة الشاعر،

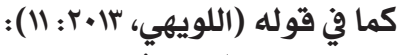

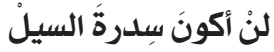
السدرةُ التي اقتلعها السيلُ في طريقه السيل

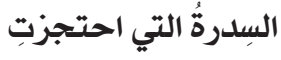
السيل وراءها

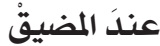
السِدرةُ التي

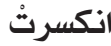

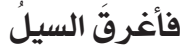

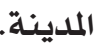

فالماء نواة النص المركزية، وبؤرته الدالة، يعكس طوفان الحياة،

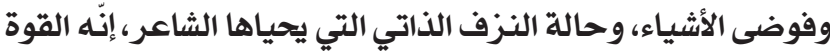
المهيمنة على فضاء النص، ينفتح على رغبات الشاعر ليعانق رؤاه

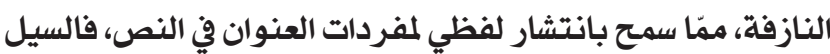
والسدرة يتبادلان الحضور والامتداد؛ لممارسة فعل التأثير وتفريغ النفارئ المعنى في ذهن المتلقي، مع ضمان تماسك النص البنيوي، ودلالته

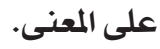
ويتحد العنوان والنص في بنية الخطاب الشعري؛ ليؤدي من خلالها

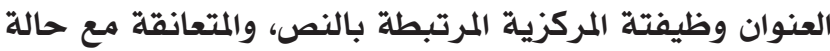
الشاعر النفسية، إذ يجنح العنوان إلى التعيين، والإشارة إلى المعنى المرتى

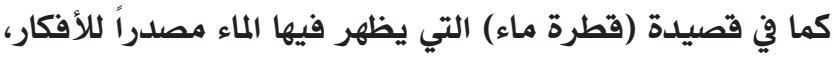

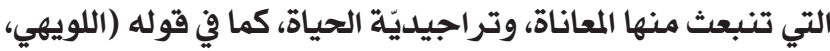

( قطرةُ ماءٍ

تسقطُ مُطر على تلى الكِتَابْ

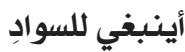

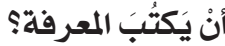
ويثري الشاعر رمزيَّة العنوان بالبعد النفسي، لذلك فإن الماء يتخذ 
لا توقظي الروحَ

دعيها غارقةً في ماءِ السديه

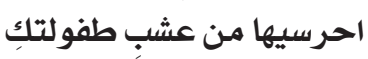

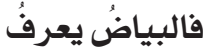

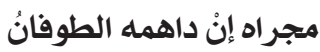

فقد احتلت العلامات المائية حيّزاً واضحاً من التشكيل اللغوي الفوان

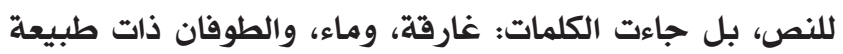
ناهضة في حوارية المشهد الشعري، وبنيته الدالة، أبرزت أنماطاً لغوية كاشفة عن تجربة الشاعر. ولعلّ هذه الانفعالية الواضحة حملت الشاعر على اختيار مفرداته القادرة على استيعاب طاقاته الانفعالية بما يثير المتلقي بما تحمله من شحنة توترية يقوم أساسها على محور الذات الشاعرة المنفعلة بمرارة الواقع، حيث تتولّد الرؤى، وتنبثق مفردات النص فئه في

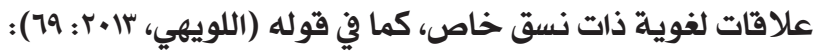
ليسن حولي ماء في فمي الماءُ أنماء فما أتكلهُ إلا بالإشارة إذ حمل توظيف الشاعر للفردة الماء دلالة القمع الفكري الذي يحياه،

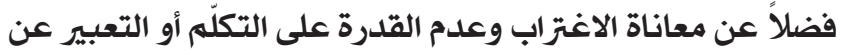
أفكاره. فالشاعر يغوص في أعماق المياه جاعلاً منها معادلاً موضوعياً

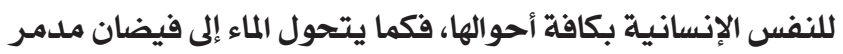
فإن النفس البشرية قد تتحول من الخير إلى الشر، ممّا يُحيّل إلى إلى

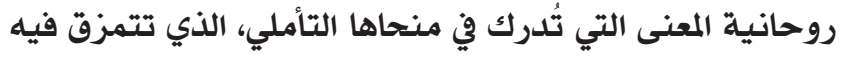

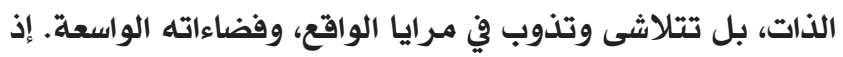

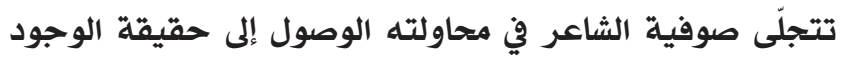

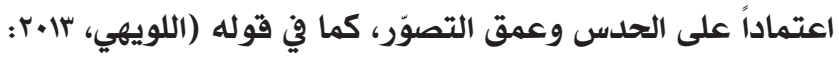

$$
\text { وحدي أدركُ }
$$

أنَّ جفافَ يديّي

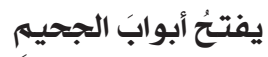

لأسماكِ البحيرة ابوابة

لذا أبقى بعيداً

يقتلني العطشُ بقد

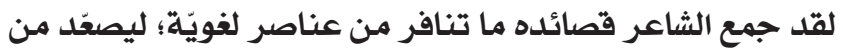

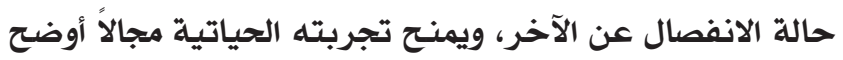

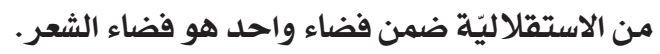

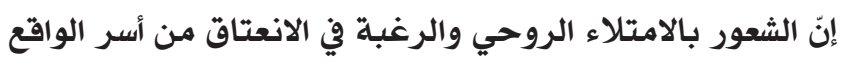
ميزة في واضحة في شعر عوض اللويهي، فهو دائم النزوع إلى السفر في ثنايا اللغة؛ ليقتنص لحظة الحله والحنين التي تجعل من الماء

حياة متجددة.

"- الماء مولّد للصورة تعذّ الأمكنة المائية كالنهر والبئر والبحيرة والبحر من الأمكنة المانحة للحياة في كثير من النصوص الإبداعية بوصفها أمكنة ذات الاتهر
تتجلّى في مفردات النص الشعري وتر اكيبه وصوره الفنية.

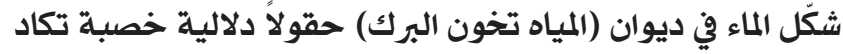

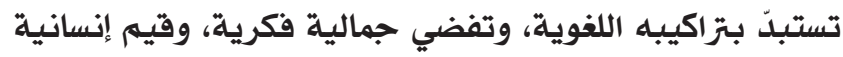

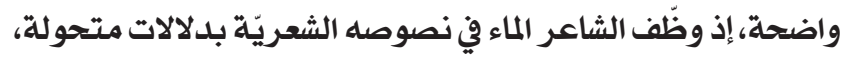
تتناسل فيما بينها لإبراز رؤية الشاعر.

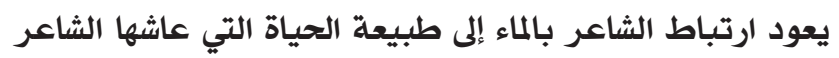
في وطنه عُمان، أو تلك الأمكنة التي سحرته في أستراليا، التي كتب التباء

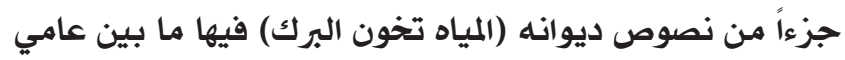

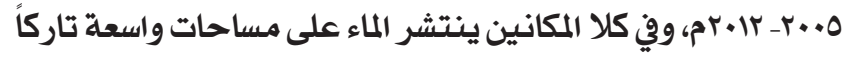

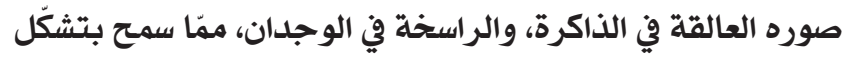
لغوي تنفلت فيه الكلمات من المخيلة لتُصاغ رؤى، وفضاءات الوحات حالمة ولة.

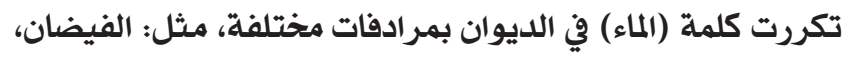

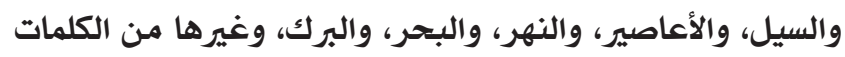

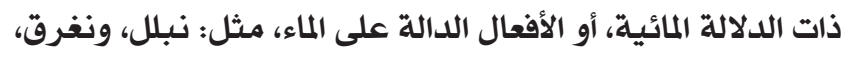

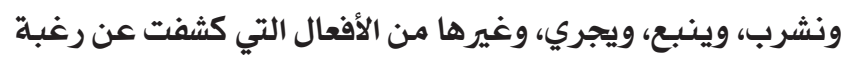

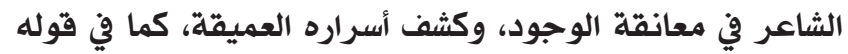

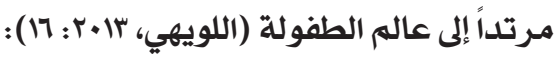
أيتها الأم

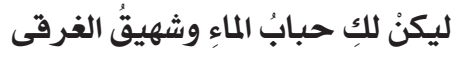
لتكنْ لكِ بالوناتُ أعيادِ الميلاد

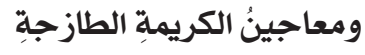
على ضفافِ المائدة فالنص يكشف عن تحكّم شعريّة الماء في إنتاج المعنى المنفتح على فئل

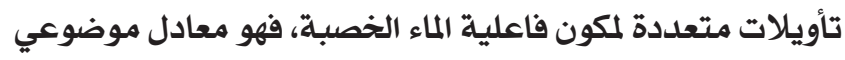

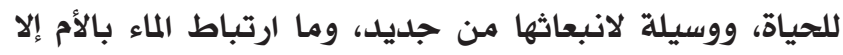

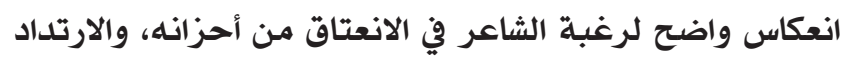

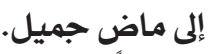
إن توظيف الشاعر لمفردات الماء أنتج بنية لغوية ذات طاقة معرفية وجمالية واضحة، استطاع من خلالها الشاعر تجسيد تجربته الشعرية وفق معجهم لغوي خاص، يستند إلى موقف إنساني، يمارس

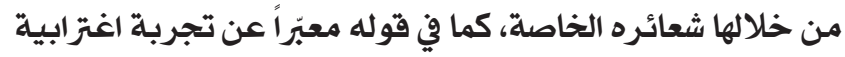
مؤلمة (اللويهي، با. مr: 9V):

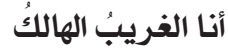
على ضفافِ الأنهار لا العشبُ على البحيرة آواني ولا التزابُ على عتبةِ البيت

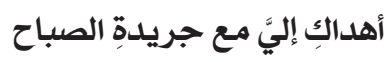
فالماء يوحي بالعمق بشكل جعله يتحول من بن طبيعته الحياتيّة إلى

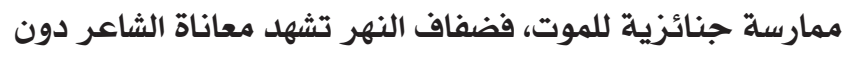

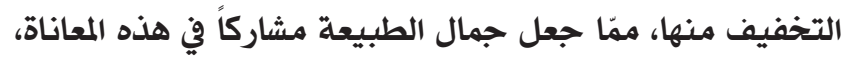

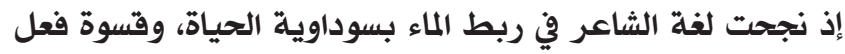
الموت فيها. وقد تعكس لغة الشاعر بعداً تلدميريّاً للماء، يُفقد الحياة معناها،

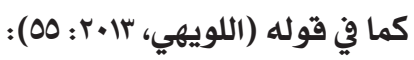




$$
\text { في الانفلات من أسر الواقع. }
$$

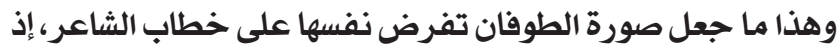

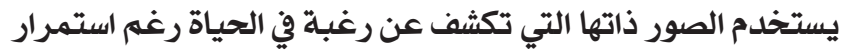

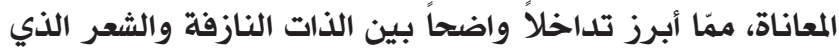

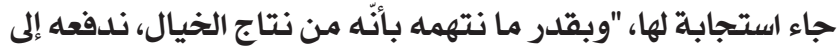

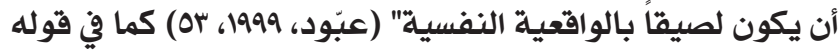

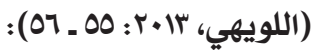

لا لا توقظي الروح دعيها غارقةً في ماء السديه احرسيها من عشب طفولتكِك

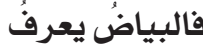
مجراه

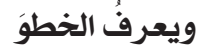
إنْ تعثرَ بالصاعقة

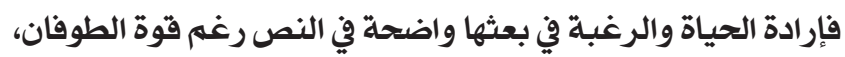
إذ امتلك الشاعر طاقة تخييلية أخرجت المفردات من سياقها الواقعي؛ لتفيض بالمجاز المعمّق لقيمة الحياة.

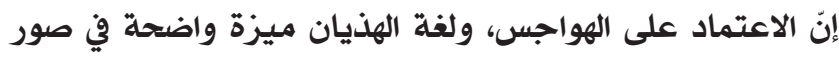

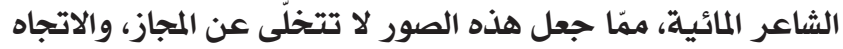

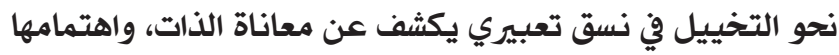

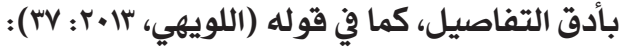

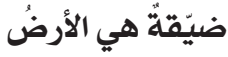
كقطرةِ ماءِ وفي السحابةِ متَسعُ لاختصام الرُعودُ صغير" هو سنُ القلم

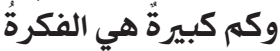

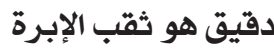
وكبير هو الخوف من العري الابرة العري متماسكة هي الصخرة ولكن نبتة صغيرة قادرة على خرق هذا التماسك فقد أعان الماء الشاعر على تجسيد رؤيته الفكرية، وبيان تجلياتها

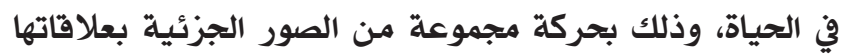

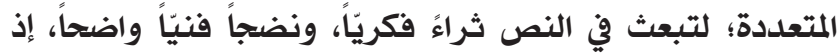

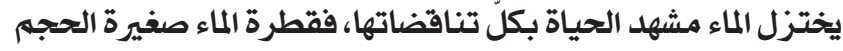

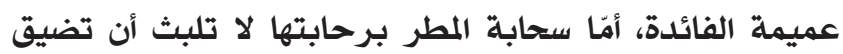

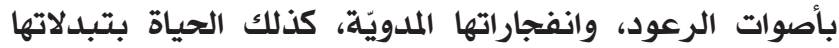
المستمرة، تتزاحم فيها الأحداث بما تبعثه من آلام المعذبين.

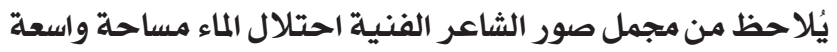

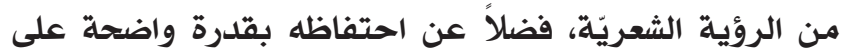

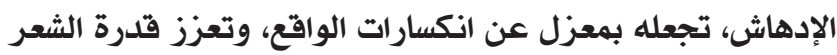
التخييلية في الاعتداد بالماء بوصفه قيمة الإدها حياتية وبؤرة جمات جمالية

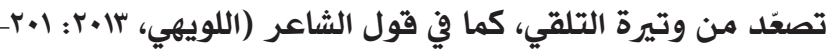

طبيعة اتَصالية تمتلك مخزوناً فكريًاً وإيحائيَاً خصباً، وهي فضلاً عن ذلك يمكن توظيفها في العمل الأدبي بوصفها وائيا "بؤرة محركة

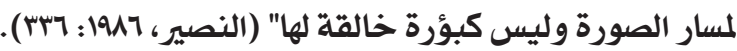

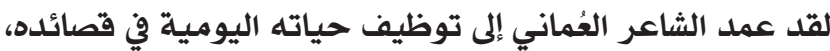
إذ أخذ ينقل "من خلالها ملامح الطبيعة، ويُبداع فيها، ويعبَّر عنها

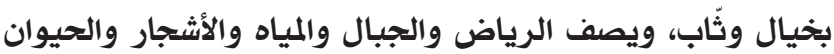

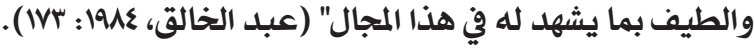

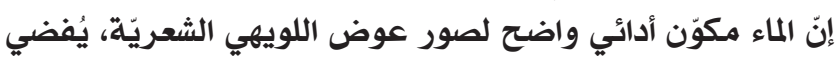

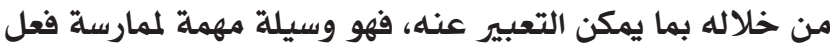

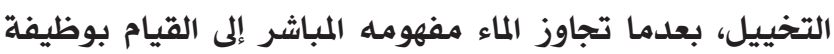

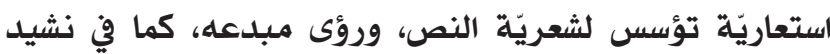

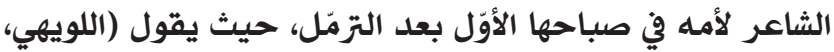

: (10,r.r. (1) كُلَّما كشفتِ عنا غِطاءُ النسيبان

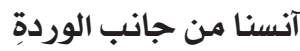

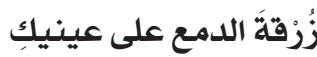
أيتها الأم كُلَّما غَسلنا أعناقنا بالماء لوتِ الريخح رقابنا

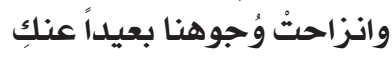

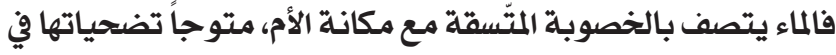

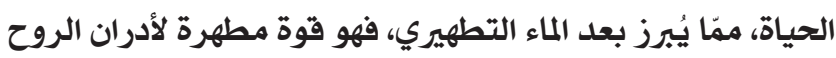

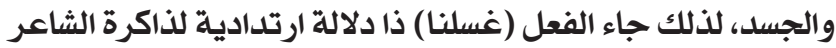

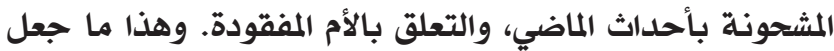
الصور المائية أقرب للتذوق، ووسيلة مؤثرة من وسائل التعبير،

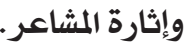
تبعث المرأة الحياة في الشعر، كذلك يفعل الماء في الأرض اليباب، ممًا يكشف عن العلاقة الوثيقة التي تربط الماء بالمرأة فكلاهما يمناء المانحان

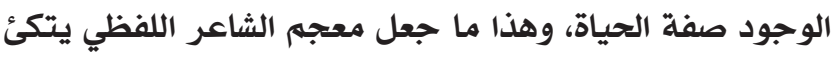
كثيراً على مفردات الماء، وتوظيفها في سياق أنثوي، تتخفقى فيه

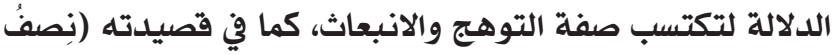

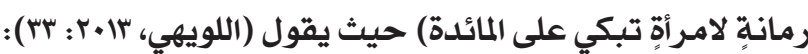

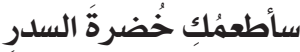

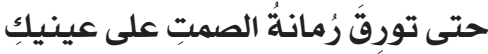

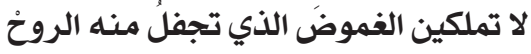

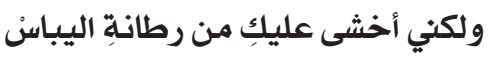

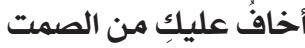
كخوفي من النهرِ عندما ينقلبُ على ضفتيه إنّ دلالة الصورة الشعريَة المائية البعيدة أو الداخلية حاضرة

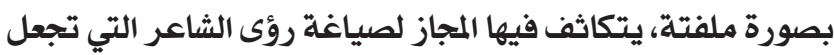

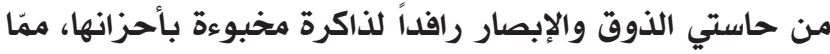

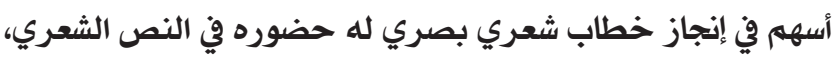
يتدفق بصور تخييلية من عالم اللاوعي تجعل من النهائ النهر في هيجانه مادة تصويرية فاعلة، ومعادلاً لذات الشاعر في هواجسها، ورغبتها 
تأثر الجنس المستضيف بخصائص الجنس الآخر، الضيف في خضوع تام لمتطلبات الخطاب، لذلك فإن الماء ظهر في النص قالبا لعاطفة الشاعر بوصفه سبيل النهوض رغهم انكسارات الواقع وهزائمه المتلاحقة، ممّا جعل الشاعر يعمد إلى السرد؛ لتجسيد رؤيته الحياتية القائمة على التمسك بالحياة مهما بلغت الإخفاقات. تنشط الصيغ السرديّة في نصوص الشاعر؛ لتؤكد تصاعد الخطاب الدرامي في القصائد، ورغبة الشاعر الملحة في إظهار مشهليّة الماء

بتوالي جزئياته المكونة له، كما في قوله (اللويهي، با. بـ : 01) : كان أبي يتسلَُّ في داخلي ويربي الصخورَ التي نبتتُ في دمي داني إلى أين تمضي المياهُ على ضفِِة الحله

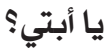
لعلّ صيغة الحوار الدرامي هي إحدى تشكّلات الخطاب المائي في

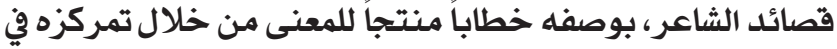

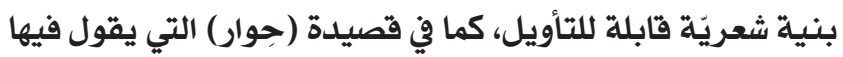

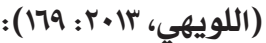
كانت سحابةٌ تقولُ لنهير يكادُ أن يجف: أعرني بعض بخارك حتى اسقيك من مائي فقال لها: ما أدراني إنْ كانتِ الريحُ ستقذفكِ بعيدا عن تدفقي

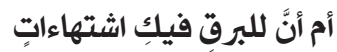

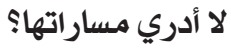
ضحكتِ السحابةُ من فطنة النهير بلَّلته ثمر مضتْ للبعيد فالشاعر يضعنا أمام حكاية تنزع فيها الشخوص المائية إلى تمثيل الأفعال تمثيلاً واضحاً فضلاً عن اشتراك التخييل في إكساب السرد الحكائي مشاهد حياتيّة تجسّد حالة الصراع التي يحياها الشاعر،

ممّا انعكس على حركة الشخوص وصر اعها مله من أحجل الحياة.

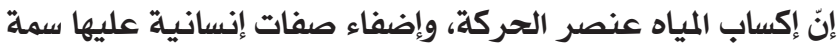
واضحة في سرد الشاعر الذي يسعى إلى إيجاد تقابل بين صور الطبيعة وأحلامه الذاتية، ممّا جعل التنقل من مشهد إلى آخر يُثري اللوحة الدرامية، ويسهم في رسم صورة لمعاناة الشاعر،

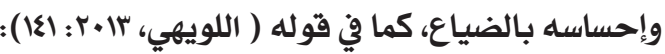
تأتينَ من حيث قال لكِ الوردُ أن تستريحي مئِ تتعبني وحشةُ الماء

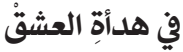
مُشبعة بالطِّة

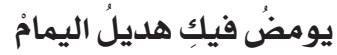
يجتاحني مطر يتساقطُ منك ونحنُ على أهبلِة البوح بالفجر هل يبردُ الجمرُ
حطَّ على الماء

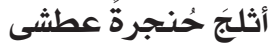

إالا وتذَكَرَ

أَنَّ الماءَ

لو كانَ يَطيز

سيصبحُ أجملَ طائر

يسكنُ في الأشجاز

وقّلوب العذراواتْ

لقد امتلك نص عوض اللويهي الشعري مرجعية فكرية واضحة تستند إلى خصوبة الماء الباعثة للأفكار، وهذا ما جعل صوري مرهية

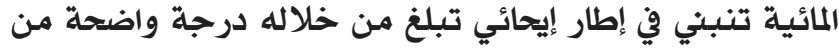

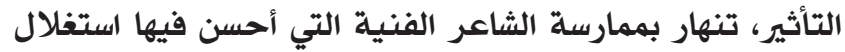

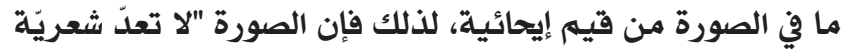
إذا كانت فاعليتها مجرد إثارة الدهشة في ذهن القارئ، وإنما بتضاعف دلالاتها على مستوى النص برمته من ترابط عناصرها

$$
\text { التصويريّة" (السليماني، 9+ +r ؛ •r). }
$$

الماء مكوّن سردي إنّ انزياح النص الشعري إلى القيام بوظيفته السرديّة مظهر واضح لنصوص الحداثة الشعريّة، بعدما أصبح البناء الشعري يتشكّل في قوالب ملحمية ودرامية تُضاف إلى قالبه الغنائي "وكان الشاعر

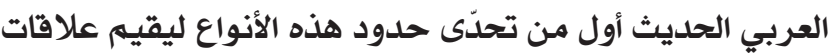
مقاربة أو مجاورة بينها بكل ما يملأ كيان هذا النص من توتر

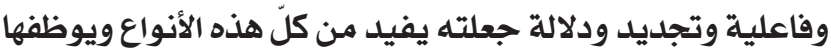

$$
\text { في عدته الشعريّة" (عباس، r +. r، V9). }
$$

إنّ التماهي بين السردي والشعري مظهر متأصل في طبيعة القصيدة العربية "إذ إنّ في كلّ وحدة من وحدات القولين الشعرئ الشعري حكاية ما،

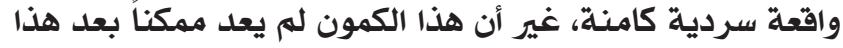

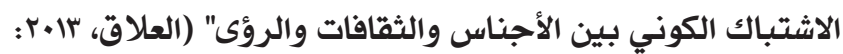

لعلّ لجوء عوض اللويهي للسرد هو عملية إنتاج جديدة لمعنى ماثل في ذهنه أو متخيّل، يسعى لتشييده في بنيان فكري قابل

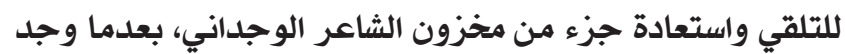
في الماء قوة فاعلة موجهة تمتلك القدرة على التغيير، كما في قوله

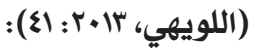

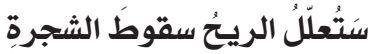

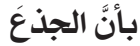

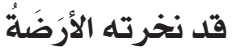
لذا له يصملْ فيْ وجِِ الريخْ

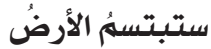
وستقول للشمسِ والريخ الماءُ قوتي وتوني

والبذرةٌ روحُ اشتهائي للصعود إذ يظهر السرد بوصفه وسيلة لجعل النص يحمل خطابا يُمارس تأثيره في الآخرين، ليحضر السرد في نسيج الخطاب الشعري، ويظهر 


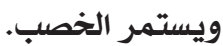

إنَ جوهر شعريَّة الماء في قصائد عوض اللويهي هي لغتها المبتكرة،

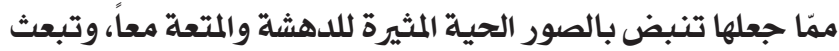

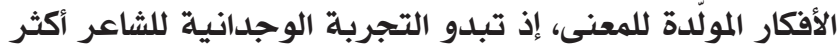

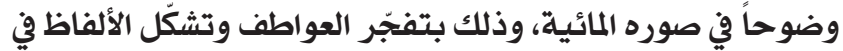

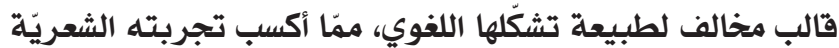

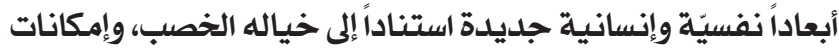

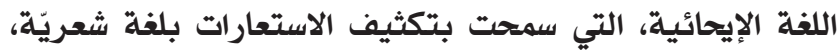

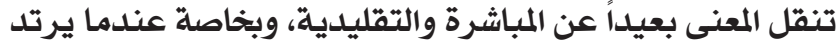
الشاعر لنفسه جاعلاً من الماء مُدخلاً مناسباً لقصائده، ومكوناً

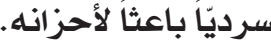
لقد ظهرت كلمة الماء في ديوان الشاعر مشحونة بدلالاتلات الخصب

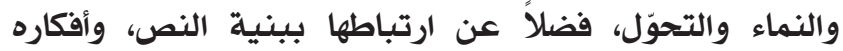

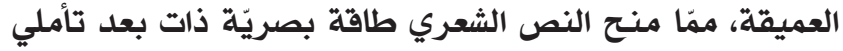

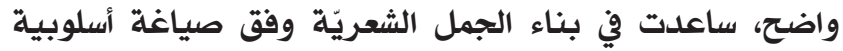

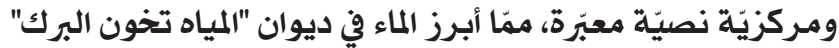
بوصفه نواة دلاليّة مهيمنة في النص الشعري، ذات ارتئة ارتباط وثيق بوقائع نفسية واجتماعية وبنائية، تُحيل إلى فاعلية فكرية مولَّة الندة للمعنى.

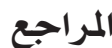

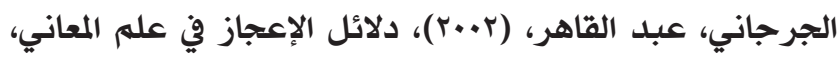
تحقيق ياسين الأيوبي، طا، بيروت صيدا، المكتبة العصريَّة.

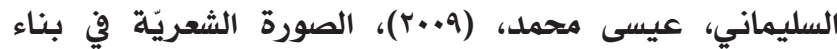
القصيدة العُمانية (•191- •199م)، طا، دار كنوز المعرفة العلمية

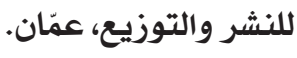

العلاق، علي جعفر، (rا.r)، في مديح النصوص، طا، دار فضاءات

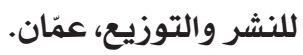

اللويهي، عوض، (ז/ (T)، المياهُ تَخُونُ البركَ، طا، دار فضاءات للنشر

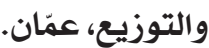

النصير، ياسين، (1917)، إشكالية المكان في النص الأدبي (دراسات نقدية)، طا، دار الشؤون الثقافية العامة، بغداد. النصير، النالية ياسين،

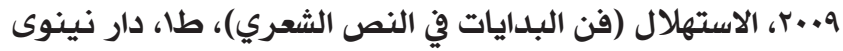
للدراسات والنشر والتوزيع، دمشق.

النصير، ياسين، (rا.r)، شعريَّة الماء (مقالات في نقد الشعر)، طا، دار سردم للنشر والتوزيع، السليمانية، العراق.

باشلار، غاستون، (V +.r)، الماءُو والأحلام (دراسة عن الخيال والمادَة)،

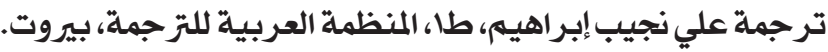

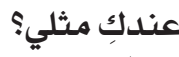

ولعلَ هذا الوجد الشفيف للذات سمح بحضور درامي اتكأ عليه

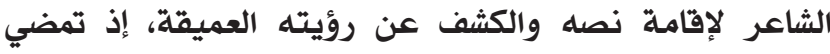

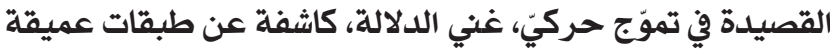

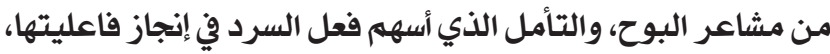

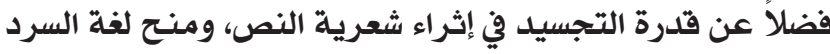

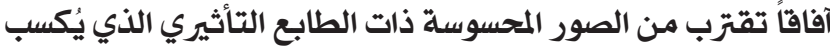

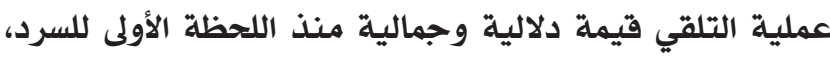
حيث ظهر الماء بوصفه شخصية محورية يقوم عليها فعل السرد، وتنبني من خلاله الرؤى ذات الطبيعة المتحفزة للحياة.

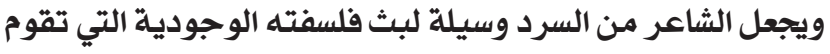

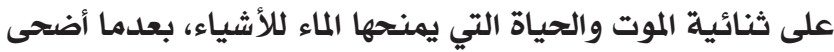

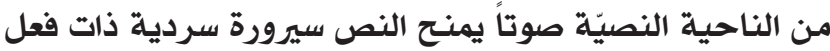

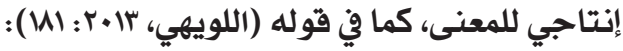
يتساقط الجدار الطيني تدريجياً بماء المطر الجدار الطيني الذي يفقد أجزاءه

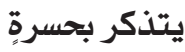

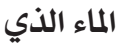

استطاع أنْ يجعله سميكاً

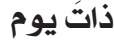
عند بنائه لعل الحضور السردي في النص السابق تشعَب في جانبين: دلالي،

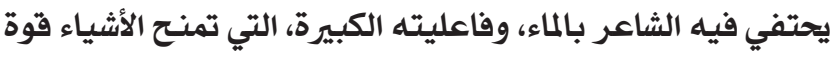

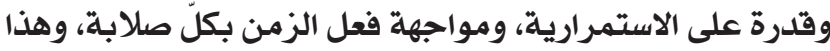

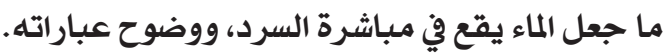

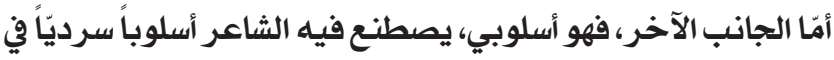

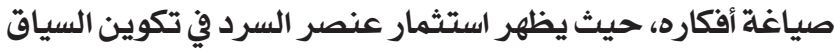

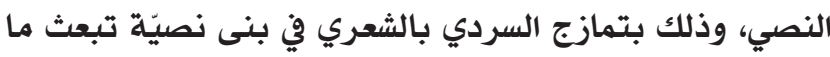
تختزنه الذاكرة بإيقاعية الألفاظ، وجمالية التعبير.

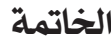

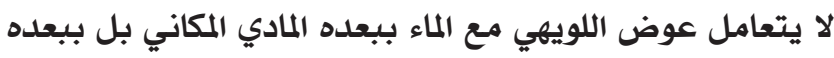

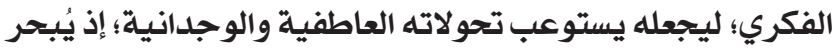

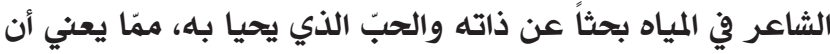

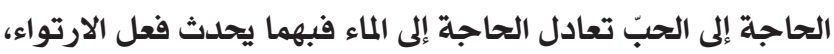

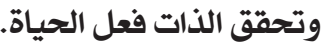
تظهر عنوانات الديوان ذات دلالة مائية يشدَ بعضها بعضاً ممَّا حقق تماسكاً في المعنى رغم اختتلاف اللفظ، فالماء هو الأمل المنشود،

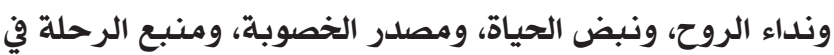

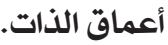
تبلدو ثنائية الحضور والغياب في توظيف الشاعر للماء جلية، إذ إذ إذاء

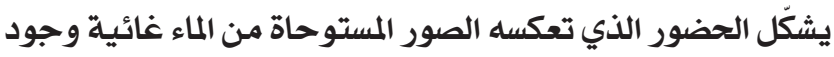

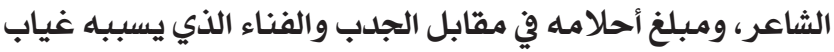
الماء، لذلك تحاول الذات جاهدة التوحُل مع الطبيعة لتنبعث الحياة 


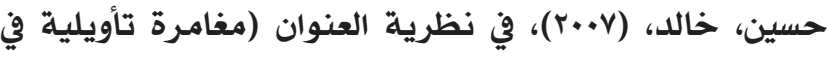
شؤون العتبة النصيّة) طا، دار التكوين للتأليف والترجمة والنشر، دمشق.

ريكور، بول، (r.+r)، نظرية التأويل (الخطاب وفائض المعنى)، ترجمة سعيد الغانمي، طا، المركز الثقافي العربي، الدار البيضاء.

شبانة، ناصر، (9.+r)، الرؤى المكبّلة (دراسات نقدية في الشعر)، طا، دار فضاءات للنشر والتوزيع، عمّان.

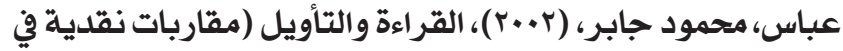
تحليل الخطاب الأدبي الحداثي في العراق) طا، دار الحراء الكرمل، عمّان.

عبد الخالق، علي، (عاهي)، الشعر العُماني (مقوماته واتجاهاته

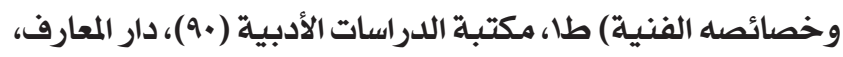

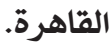

عبّود، حنا، (1999)، النظرية الأدبية الحديثة والنقد الأسطوري،

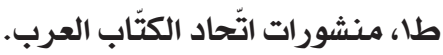

